\title{
Research Hotspots and Trends on Media Literacy in CNKI Based on Visual Analysis
}

\author{
Qi Su', Ying Chen ${ }^{2 *}$ \\ ${ }^{1}$ School of Education Science, Nanjing Normal University, Nanjing, China \\ ${ }^{2}$ Teachers Development Center at Gusu District in Suzhou, Suzhou, China \\ Email: *yingchen_tdcgds@163.com
}

How to cite this paper: Su, Q., \& Chen, Y. (2020). Research Hotspots and Trends on Media Literacy in CNKI Based on Visual Analysis. Open Journal of Social Sciences, 8, 361-376.

https://doi.org/10.4236/jss.2020.85025

Received: April 27, 2020

Accepted: May 26, 2020

Published: May 29, 2020

Copyright () 2020 by author(s) and Scientific Research Publishing Inc. This work is licensed under the Creative Commons Attribution International License (CC BY 4.0).

http://creativecommons.org/licenses/by/4.0/

\section{(c) (i) Open Access}

\begin{abstract}
There are 957 published papers on media literacy included in CSSCI database of CNKI taken as the research object, and the software CiteSpace is used to conduct visual analysis on the author, research institutions and keywords. In the end, the high impact authors, high impact institutions, research hotspots and development trend of media literacy research in CNKI are revealed. The research results show that in the past decade, the research on media literacy in CNKI has been developing continuously. The relevant researches are mainly conducted by the team of Shuyu Zhang of Nanjing Normal University and the team of Xiaohui Chen of Northeast Normal University; in addition, Communication University of China is also a highly influential institution in the field of media literacy research. It can be seen that researchers who study education or media have paid more attention to the media literacy research, but the existing problem is the estrangement and less cooperation between different research institutions. In terms of research content, in the past and in the future for a long time, media literacy education will still occupy a dominant position. However, the development of media literacy research has never stopped. In the future, researchers are likely to continue to expand the research scope of media literacy and make it a more interdisciplinary research field.
\end{abstract}

\section{Keywords}

Media Literacy, Hotspots, Trends, CiteSpace

\section{Introduction}

The concept of Media Literacy derived from England in the 1930s (Cubbage, 2018). It is a classical concept which has been characterized by Western knowledge and perspectives for many years. In 1992, the American media literacy research center defined media literacy as follows: the ability to interpret and create 
personal meaning from the hundreds, even thousands of verbal and visual symbols we take in everyday through television, radio, computers, newspapers and magazines, and of course advertising. It's the ability to choose and select, the ability to challenge and question, the ability to be conscious about what's going on around you and not be passive (Thoman, 1999). Several years later, Siverblatt and Eliceiri in their Dictionary of Media Literacy define media literacy as a critical-thinking skill that enables audiences to decipher the information that they receive through the channels of mass communications and empowers them to develop independent judgments about media content (Siverblatt \& Eliceiri, 1997; Potter, 2010). In short, it is the skillful collection, interpretation, testing and application of information regardless of medium or presentation for some purposeful action (Anderson, 1981; Potter, 2010). Though it has several names of similar significance such as media education, media literacy and so on, most scholars agree and accept the use of "Media Literacy" to describe it in China (Zhao \& Zhang, 2015).

Since media literacy was introduced into China in the 1990s, it has developed rapidly in China. Many scholars in China have combed the development frontier and trend of media literacy related fields outside China. For example, Yiqun Geng and Yue Xu (2014) combed the research status and development trend of media literacy courses outside China; Mengcheng Zhao and Weiqin Liu (2015) studied the history, problems and development trend of media literacy education in the United States; Yiqun Geng and Pengfei Wang (2016) reviewed the evolution trend of EU media literacy policy in the digital environment. Meanwhile, the development frontier and trend of media literacy related fields inside China were also combed by some researchers. Pengze Wu and Shiyou Du (2011) analyzed and summarized the results of College Students' media literacy research conducted from 2004 to 2010, and Li Zhao \& Shuyu Zhang, (2015) analyzed the research hotspot and trend of media literacy conducted from 2012 to 2013.

Based on the background listed above and combined with CiteSpace 5.2 visual analysis tool, bibliometric analysis was used to sort out, analyze and present the research achievements of media literacy from 2010 to 2019 in China National Knowledge Infrastructure (CNKI), where most papers of researches conducted by Chinese are published. By analyzing the distribution of authors, research institutions and keywords co-occurrence among the media literacy researches, etc., the development trend and research context of media literacy in China in the past decade are being visually shown. In this way, the follow-up researches may obtain some references.

\section{Data Source and Visual Tool}

\subsection{Data Source}

The sample used was selected from CNKI, which is the world's largest Chinese journal full-text database, and has abundant literature resources as well as sound retrieval functions (Fu et al., 2015; Tian et al., 2020). After advanced search was chosen on the website of CNKI, the subject word "media literacy" or "media li- 
teracy" (Actually, two different Chinese words were selected as the search field, which were the same after being translated into English) was entered for title search. Additionally, the publication time limit is 2010-2019, and the source category is limited to the database of Chinese Social Sciences Citation Index (CSSCI). The search was conducted on January 10th, 2020. In the end, 992 publications were obtained in total (see Figure 1). Text in the figure is in Chinese instead of English because the search results will be different if displayed in English). Excluding irrelevant publications such as advertisements, notices, press releases, etc., 957 published papers are identified as valid samples.

\subsection{Visual Tool}

The search results were exported in Refworks format and converted into identifiable data in order to be more suitable for us to analyze by CiteSpace. Then the data were imported into CiteSpace, the visualization software developed by Dr. Chaomei Chen's team. CiteSpace can measure the paper in a specific field to explore the research hotspot and development trend in a certain discipline or field. The function of keywords co-occurrence analysis in the software can directly reflect the research hotspot and frontier trend in a certain research field. Here CiteSpace 5.2 is used to visually analyze 957 related papers about media literacy in CSSCI database of CNKI from 2010 to 2019. Document time was limited from 2010 to 2019; Time slice was set as 1 year; Document source was selected as "Title", "Abstract", "Author Keywords (DE)" and "Keywords Plus (ID)"; Threshold was set as "Top $\%=50 \%$ "; Visual selection was selected as "Cluster View-Static" and "Show Merged Network". Then, the knowledge graph was drawn from three aspects of author, research organization and key words of the papers. In addition, we combed the research topics with literature study.

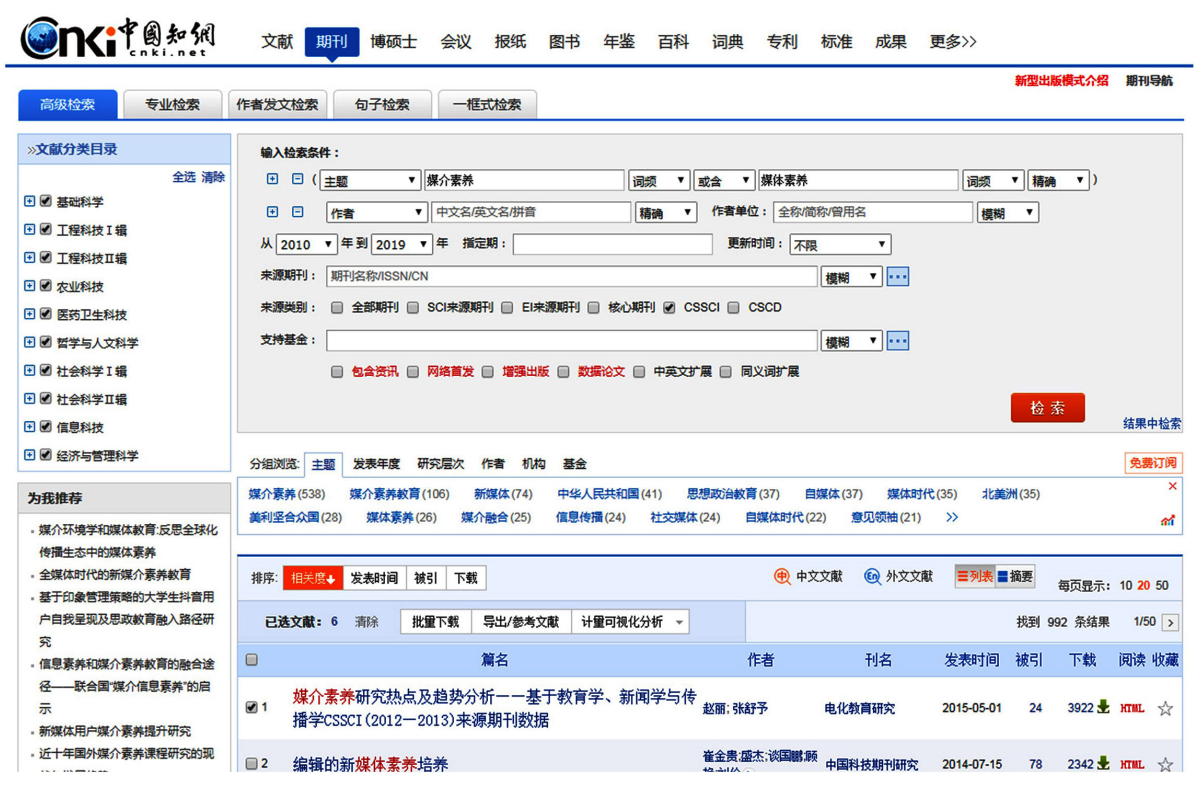

Figure 1. Results of advanced search in CNKI (2010-2019). 


\section{Visual Analysis}

\subsection{Number of Media Literacy Papers}

Through the quantitative analysis of the papers, the number of media literacy papers between 2010 and 2019 is shown in Figure 2. As is shown, the general popularity of media literacy keeps at a high level. From 2010 to 2012, the number of published papers remained stable, but declined briefly in 2013, and rebounded from 2014 to 2015. By 2016, the number of published papers rose significantly and reached the peak of nearly ten years with 106 papers. However, it is worth noting that the number of published papers decreased significantly in 2017, then reached the lowest level in 2019. In recent years, the overall trend of research has been declining slowly.

It is obvious that we shouldn't only consider papers published between year 2010 and 2019 while seeking for the reasons. As is known, researches on media literacy have started since around 2000 in China. Actually, theories and practices about media literacy research have become relatively mature when time came to 2010. What Figure 2 does not show is that from 2000 to 2009, the number of papers on media literacy research published each year is increasing year by year. In this period, media literacy research in China is still in the transition period from germination to rapid development. After about ten years of theoretical accumulation, the number of media literacy research papers broke through 100 for the first time in 2010, reaching 104, and from this year on, the number of papers published each year began to stabilize. Although there are some fluctuations in the latter number, especially between the year of 2013 and 2016 there were several fluctuations. This kind of instability exactly confirms the fact that the field of media literacy research has become mature. But it is significant that the amount of papers published in the field of media literacy research is slowly decreasing from the given trend dotted line. One of the most important reasons is that there have been many researches on media literacy and the task of constructing its theoretical framework has been relatively perfect. The development direction of this field will be learned later in this paper.

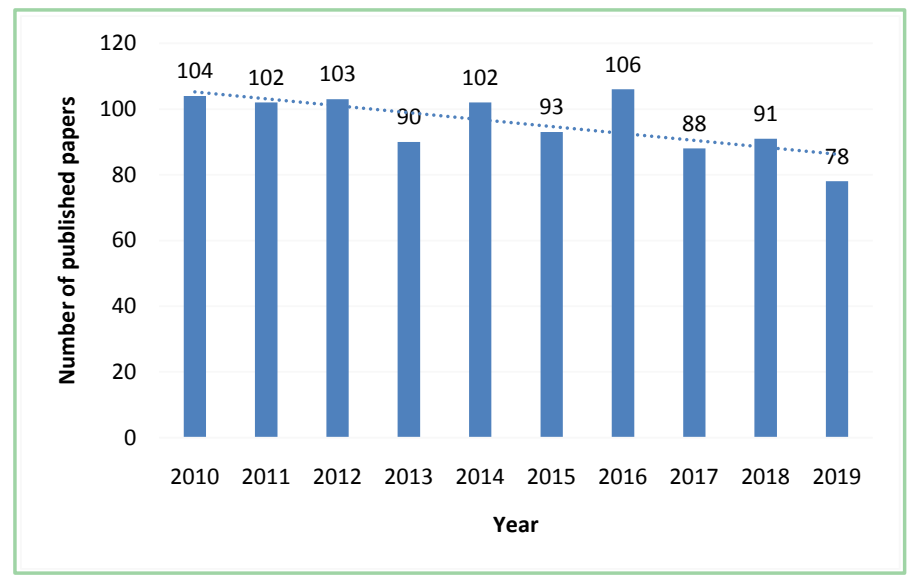

Figure 2. The number of published papers in CNKI (2010-2019). 


\subsection{Core Authors and Research Institutions}

Select "Author" and "Institution" in the node type of CiteSpace, and the high impact authors and research institutions are shown in Table 1. It can be seen from the table that Shuyu Zhang, Xiaohui Chen, Yanqiu Zhang and Fan Wang are in the top four in terms of the number of publications with greater advantages. Additionally, Communication University of China, Nanjing Normal University, Northeast Normal University and Communication University of Zhejiang are in the top four in terms of the number of publications with greater advantages. Generally speaking, communication universities and normal universities pay higher attention to media literacy than other types of the universities.

In order to find out the core academic groups of media literacy research, a co-occurrence graph of authors of media literacy research (Figure 2) was generated. In the graph, the node is the author's name; The node size represents the number of published papers; The node ring represents the annual ring; The label size represents the centrality; The lines describe the cooperation between authors. According to the network structure and the clarity of clustering, CiteSpace provides two indexes: module value ( $\mathrm{Q}$ value) and average contour value ( $\mathrm{S}$ value), which are used as the basis for evaluating the mapping effect. Generally speaking, $Q$ value in the interval $[0,1]$ and above 0.3 mean that the community structure is significant. When $\mathrm{S}$ value is above 0.7 , clustering is highly efficient and convincing. If it is above 0.5 , clustering is generally considered reasonable. There are 53 nodes and 18 connections in the author cooperation network. The overall density of the network is 0.0131 . Q value is 0.85 , which is above 0.3 , and $S$ value is 0.23 . It shows that the author social group formed by the media literacy research is significant. As is shown in Figure 3, the media literacy research has formed two cohesive research teams with Shuyu Zhang and Xiaohui Chen as the core respectively. Though field of media literacy research is developing continuously, the number of core researchers is relatively small, with only two persons.

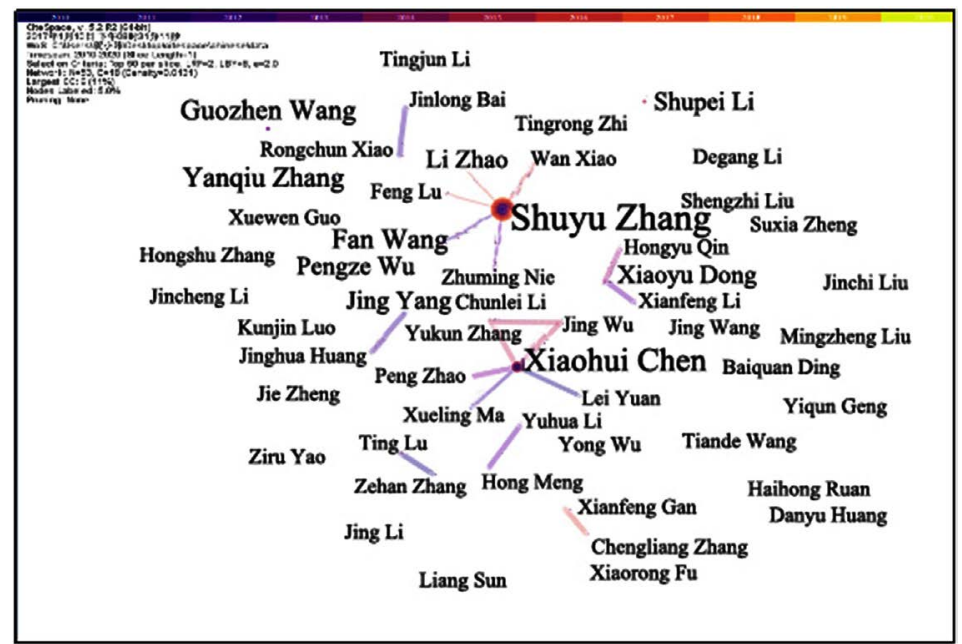

Figure 3. The co-occurrence graph of media literacy authors in CNKI (2010-2019). 
Table 1. The co-occurrence graph of authors/research institutions of media literacy in CNKI (2010-2019).

\begin{tabular}{cccccc}
\hline No. & Frequency & Core Authors & No. & Frequency & Research Institutions \\
\hline 1 & 28 & Shuyu Zhang & 1 & 33 & Communication University of China \\
2 & 13 & Xiaohui Chen & 2 & 31 & Nanjing Normal University \\
3 & 5 & Yanqiu Zhang & 3 & 25 & Northeast Normal University \\
4 & 5 & Fan Wang & 4 & 18 & Communication University of Zhejiang \\
5 & 4 & Xiaoyu Dong & 5 & 11 & Sichuan University \\
6 & 4 & Guozhen Wang & 6 & 7 & Xuzhou University \\
7 & 4 & Shupei Li & 7 & 6 & Zhengzhou University \\
8 & 4 & Jing Yang & 8 & 6 & Nanjing University \\
9 & 3 & Pengze Wu & 9 & 4 & Chang'an University \\
10 & 3 & Li Zhao & 10 & 4 & Southwest University \\
\hline
\end{tabular}

In order to find out the core institutions of media literacy research, a co-occurrence graph of media literacy research institutions (Figure 4) was also generated. There are 59 nodes and 11 connections in the institution cooperation network. The overall density of the network is 0.0064 . Q value is 0.93 , which is above 0.3 , and $S$ value is 0.20 . It shows that the research institution community formed by media literacy research is significant. As is shown in Figure 4, there are four research institutions with Communication University of China, Nanjing Normal University, Northeast Normal University and Communication University of Zhejiang as the core institutions. However, it is worth noting that there is less cooperation between authors of different media literacy institutions, and the research is relatively scattered, so there is no scientific research group consisting of different institutions.

\subsection{Keywords Analysis}

\subsubsection{Keywords Co-Occurrence Analysis}

The keywords with high centrality and frequency represent the common concerns of researchers in a period of time, that is, the research hotspot. As a measure of the power of nodes, centrality reflects the importance of anode in the network. The higher the co-occurrence frequency of keywords and the higher the centrality of points, the more important the nodes are in this field. In addition to the basic research keywords "media literacy" and "media literacy" (Actually, these two Chinese words were similar but different before being translated to English), the co-occurrence graph of media literacy research keywords from 2010 to 2019 is shown in Table 2. The top three keywords with the highest frequency in the field of media literacy research also have the highest centrality, namely, 109 times of "media literacy education" with a centrality of 0.18 , then 81 times of "new media" with a centrality of 0.16 , and 77 times of "college student" with a centrality of 0.14 . 


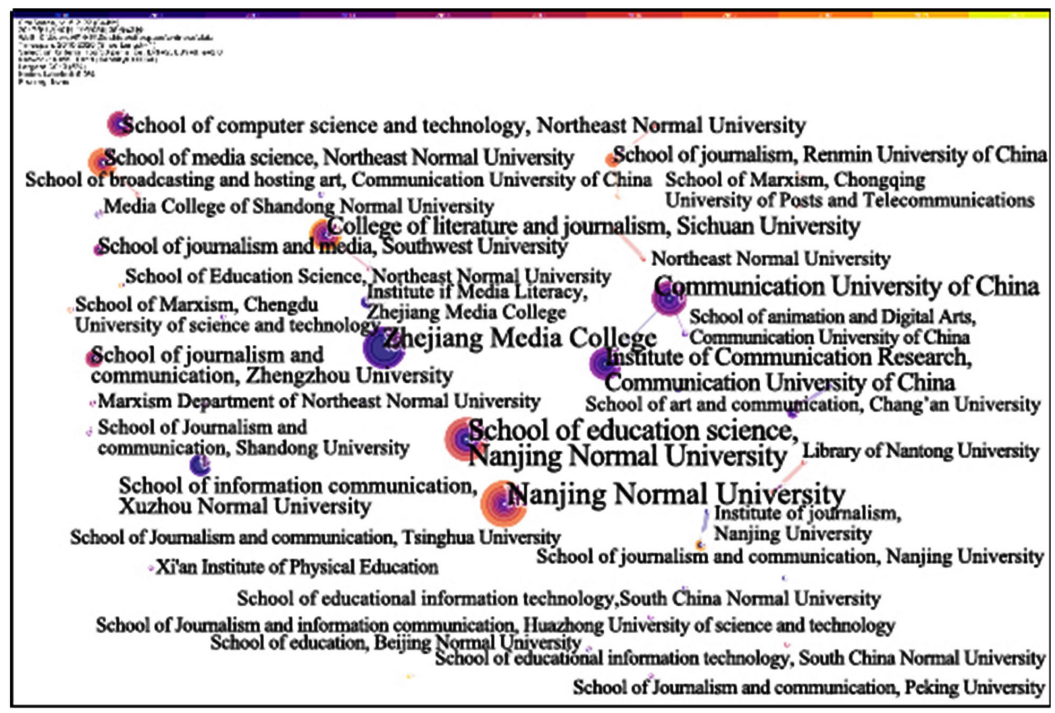

Figure 4. The co-occurrence graph of media literacy research institutions in CNKI (2010-2019).

Table 2. The co-occurrence of media literacy research keywords in CNKI (2010-2019).

\begin{tabular}{ccccc}
\hline No. & Frequency & Centrality & Year & Keywords (in English) \\
\hline 1 & 109 & 0.18 & 2010 & Media literacy education \\
2 & 81 & 0.16 & 2010 & New media \\
3 & 77 & 0.14 & 2010 & College student \\
4 & 26 & 0.01 & 2014 & Self-media \\
5 & 20 & 0.08 & 2010 & Media \\
6 & 19 & 0.03 & 2010 & Teenagers \\
7 & 19 & 0.03 & 2010 & Information literacy \\
8 & 19 & 0.05 & 2011 & Ideological and political education \\
9 & 16 & 0.00 & 2010 & Media convergence \\
10 & 15 & 0.01 & 2011 & Micro-blog \\
11 & 14 & 0.01 & 2012 & Universities \\
12 & 13 & 0.03 & 2012 & Internet public opinion \\
13 & 11 & 0.05 & 2010 & Media literacy education \\
14 & 10 & 0.06 & 2010 & U.S.A \\
15 & 10 & 0.00 & 2016 & Social media \\
\hline
\end{tabular}

From the table listed above, it can be seen that the keyword "media literacy education" has the highest frequency over the last decades in CNKI. As the most practical and operational field of media literacy research, media literacy education research has attracted much attention. Additionally, researches of media literacy education are also growing mature. Now it has become a multi-level, multidisciplinary, cross disciplinary academic field (Livingstone, Papaioannou, Pérez, 
\& Wijnen, 2012). First, for a specific group of people, some scholars have explored the media literacy education research, analysis report and other empirical researches. Second, of different subjects, media literacy education could also be discussed from multiple perspectives. Third, there were some interpretations based on the perspective of media literacy education on social hot topics and events. Forth, different types of media literacy education in specific environment have also been analyzed in CNKI. Fifth, some scholars have learned and analyzed the achievements and experiences of foreign media literacy education for reference. Sixth, a small number of people discussed the transformation and establishment of media literacy education in CNKI. Seventh, some authors studied the media literacy education from different disciplines and their interrelations. Eighth, there were also some researches on the analysis of the practical problems and the interrelations between these problems and media literacy education during the process of media literacy education promoting human progress and social development.

The researches of media literacy education were oriented to college students, middle school students, primary school students and so on. Most of them were empirical researches, and the majority of the topics were related to the design of curriculums. For example, Shuyu Zhang and XiaohuiChen have been devoted to the study of visual culture and media literacy courses for many years. In the study of the development of media literacy education in different countries, that of media literacy in the United States and the United Kingdom is more frequent. Based on the above analysis, it can be concluded that media literacy education will continue to play a dominant role in media literacy research for a long period of time in the future.

In the list of high-frequency keywords, the second and third words are "new media" and "college students". The reason is not hard to understand. It is mainly because media literacy is information related literacy, and in the new media era and information age, media literacy is more important than before. Meanwhile, with the increasing research on the media literacy of the audience, the research on the media literacy of different types of audience has also increased. Actually, college students are the main research objects of media literacy. Thus, the word "college students" in the context of new media has become one of the high-frequency keywords of media literacy research.

\subsubsection{Keywords Clustering Analysis}

After setting the threshold value "Top\%" to 50\%, the keywords clustering Q value was 0.50 , and $S$ value was 0.31 , which was less than 0.5 . This indicated that the clustering was unreasonable. So the threshold was adjusted to $c, c c, c c v$, then the $Q$ value was changed to 0.50 and the $S$ value was 0.94 , which showed that the clustering structure after adjusting the threshold was significant. The result of clustering was of reference value. The clustering results gotten finally are shown in Figure 5, with a total of 18 items. The 18 clustering results are arranged by numbers from 0 to 18 according to the number of keywords contained. The 


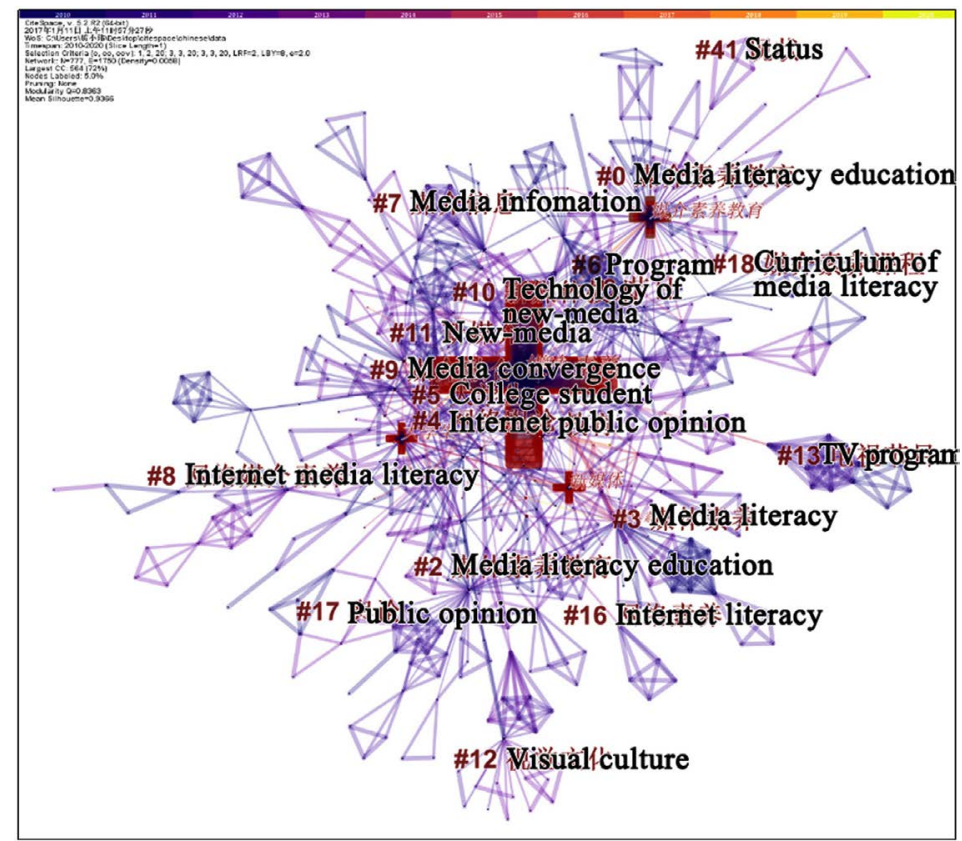

Figure 5. The keywords clustering graph of media literacy research field in CNKI (2010-2019).

smaller the sequence number is, the more keywords are included in the clustering results, and the larger the category is. In fact, CiteSpace clusters and counts the closely related keywords in the existing co-occurrence network by algorithm, and the one with the largest count in the same cluster is selected as the representative of the category.

As is shown in the figure, "media literacy education", "new media" and "Internet media literacy" are the largest three among 18 categories. Some reasons and research status about the former two have been elaborated earlier. Now, take a brief look at the latter one, Internet media literacy.

According to the 44th statistical report on the development of China's Internet, by June 2019, the number of Internet users in China had reached 854 million, an increase of 25.98 million compared with the end of 2018, with a penetration rate of $61.2 \%$ and an increase of $1.6 \%$ compared with the end of 2018 . China's mobile Internet users reached 847 million, and the proportion of Internet users accessing the Internet through mobile phones reached 99.1\%, 0.5 percentage points higher than the end of 2018. At present, there are about 30 million college students in China, all of them are netizens, which play an important role in the development of the network. In August 2018, general secretary Jinping Xi pointed out at the National Conference on propaganda and ideological work: "we must grasp the correct direction of public opinion, and persist in creating a network space where the wind is clear and the gas is positive." Nowadays people are in an information and digital era of new media. As the number of netizens growing rapidly in China, Internet media literacy begins to enter the sight of researchers. 


\subsubsection{Keywords Timeline Analysis}

In essence, timeline graph is a clustering graph, only adding time to the original clustering graph. Then it shows the development of keywords in each cluster. The evolution of hotspots is shown in Figure 6. In addition, according to the timeline graph it can be roughly concluded that the development of media literacy research in the last decade. The researches related to media literacy began many years ago, and there exist some scholars having been devoted to the media literacy research for a long time in China. Between 2010 and 2019, the researches of media literacy in CNKI had a continuous and stable development, and obviously media literacy education is the most important research hotspot in the field of media literacy. Other topics are significantly less studied than media literacy education. Around 2010, most of the research topics on media literacy are concentrated and single, with media literacy education and related contents as the main research direction. With the passage of time and the popularity of new media technology, the depth of media literacy research has further developed. While media literacy education research remains a heated topic, the scope of media literacy research is gradually expanding, and the content of research is also increasing. This can be seen from the keywords and their clustering result of published papers. Thus, it can be said that the research of media literacy is still in a period of continuous development and rise. In the next long period of time, the research on media literacy will still extend and expand its scope, and absorb more contents of other disciplines for research, becoming a more representative field of interdisciplinary. For example, some people have started to study the policy and government, micro-media and micro-era, new media and self-media, mobile phones and Internet, etc., from the perspective of media literacy.

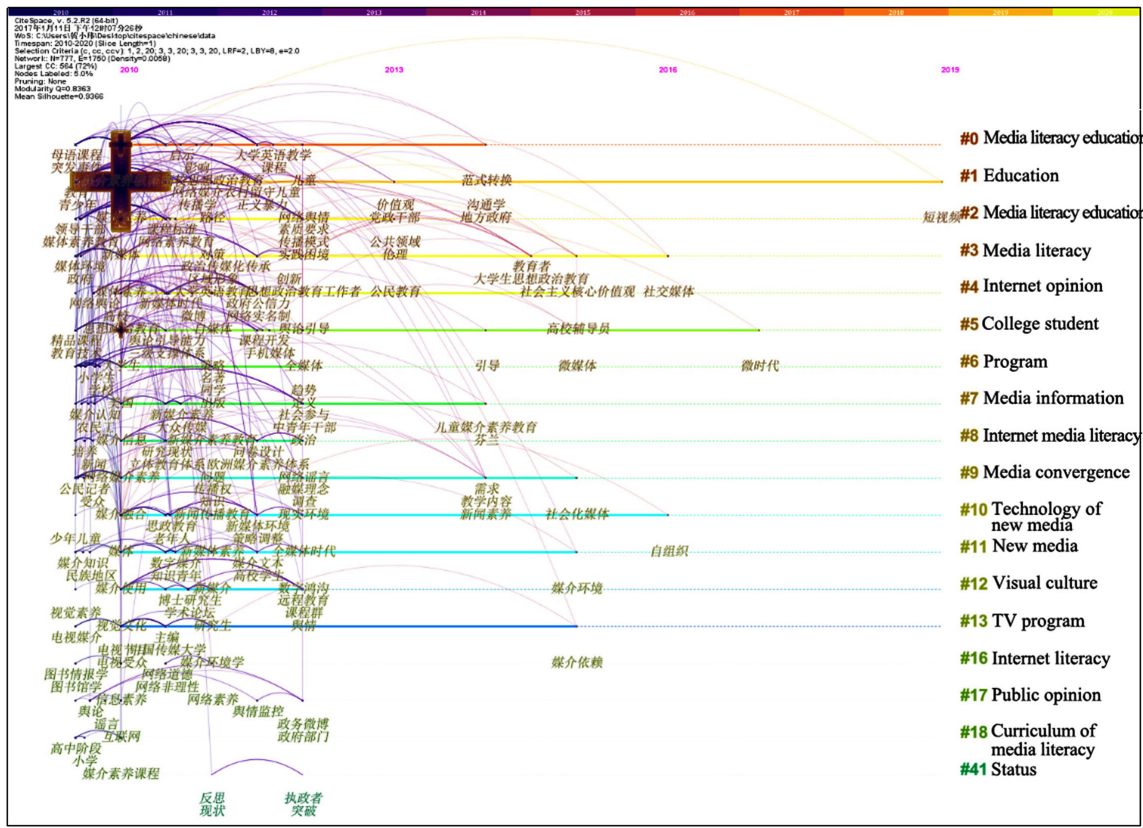

Figure 6. Timeline graph of media literacy research in CNKI (2010-2019). 


\subsubsection{Keywords Bursts Term Analysis}

Bursts refer to the words that appear more or are cited more frequently in a short period of time. The frontier and trend of the research field can be judged according to the change of the keywords frequency of the burst terms. Figure 7 shows the strongest citation bursts of media literacy keywords. We can see that "media literacy", "new media", "college students" and "self-media" are the research hotspots of media literacy. Among them, "media literacy" is mainly reflected from 2016 to 2019, "new media" from 2013 to 2019, "college students" from 2014 to 2019, "self-media" from 2014 to 2019. To a certain extent, the research frontier of media literacy in CNKI is mainly focused on the field of new media and self-media, with the target group mainly college students. Additionally, it can be inferred that researches on new media and self-media among college students are likely to occupy an important position in the next period.

\section{Discussion and Conclusion}

There are 957 published papers on media literacy included in CSSCI database of CNKI taken as the research object, and the software CiteSpace was used to conduct visual analysis on the authors, research institutions and keywords. In the end, the high impact authors, high impact institutions, research hotspot and development trend of media literacy research in CNKI were revealed. From the analysis results, several conclusions are drawn.

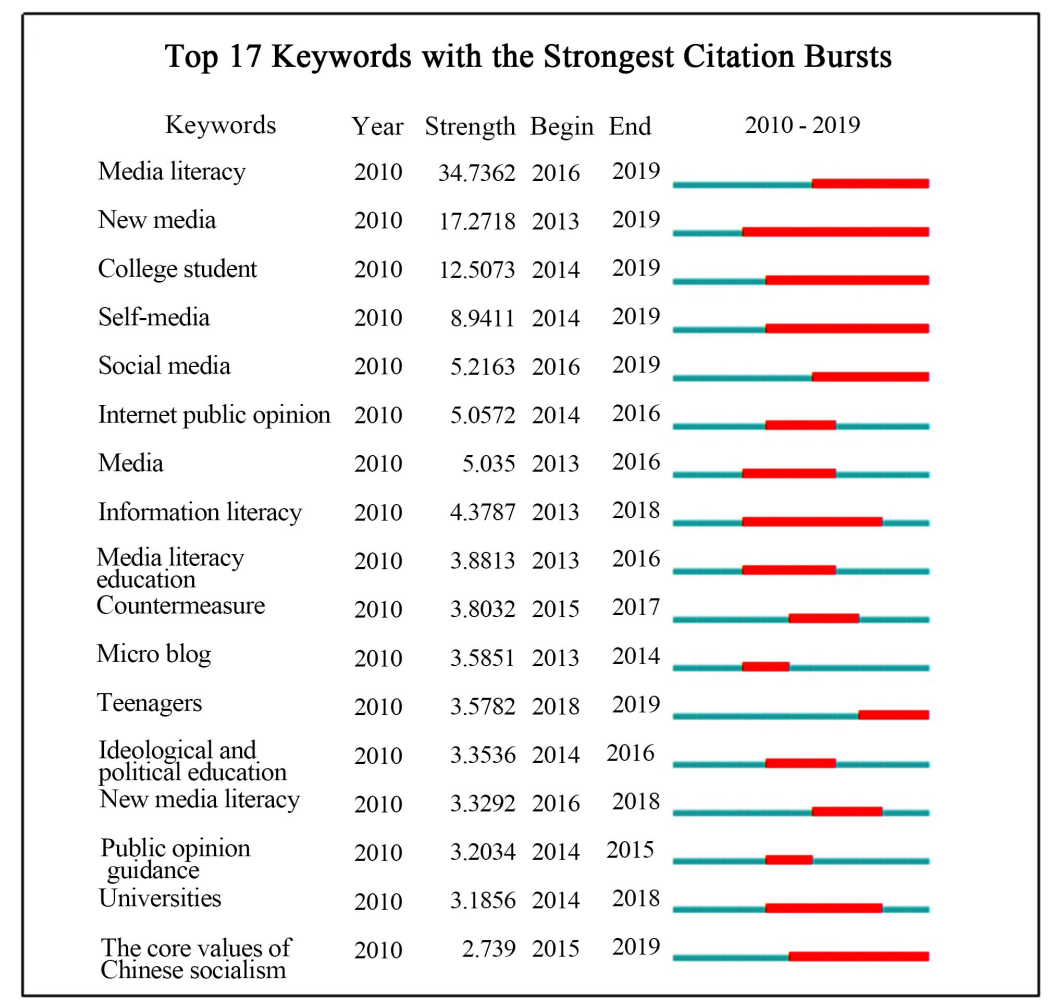

Figure 7. The bursts of media literacy in CNKI (2010-2019) (span: 1 year). 


\subsection{Status and Trend of Media Literacy Research}

In the past decade, the number of published research papers on media literacy in CNKI has a slight decline in the steady development. The topics that get the most attention are "media literacy education", "new media", "self-media", "Internet media literacy", "college students", etc.. Although the number of papers published reached a peak in 2016, the peak was not prominent and was a normal fluctuation. On the whole, media literacy research shows a slight and slow downward trend. On the one hand, the research field of media literacy has a relatively complete theoretical basis, and most of the research has been relatively mature (Frau-Meigs \& Torrent, 2009). This not only explains why the development of media literacy research is declining now, but also indicates it may slow down the future development of media literacy research. But on the other hand, the research scope of media literacy is very wide (Koltay, 2011), and the integration research with other disciplines needs to be further expanded and explored, which is likely to provide power to its development. Thus, it can be considered that the development of media literacy research will show a relatively stable trend in the future for a long time, but there will be a sustained small decline in this process.

\subsection{Relationship between Research Subjects}

There are many media literacy research institutions and core researchers in China (Cheung, 2016). From the perspective of research team, normal universities and communication universities pay more attention to media literacy than other types of schools, such as Nanjing Normal University, Northeast Normal University, Communication University of China and Communication University of Zhejiang. As for the core members of the research team, Shuyu Zhang of Nanjing Normal University and Xiaohui Chen of Northeast Normal University are typical representatives. Although various institutions and scholars have made some achievements in the past decade, it is obvious that there is a lack of cooperation among researchers from different teams, and the status of research institutions is alienated from each other. At present, most media literacy researches are just applied research and simple theoretical or practical expansion. It is known that different research institutions and researchers have their own characteristics in media literacy research (Manville et al., 2015), and their ideas and academic resources are different to a certain extent. Thus, if researches that can have a high impact on the field of media literacy research and even the whole academia are to conduct, cooperation is a great way for research institutions and researchers (Franco \& Pinho, 2019).

\subsection{Evolution and Trends of Research Topics}

From the research of high frequency keywords and clustering results, it can be seen that media literacy education has received the most attention in the past decade, and its attention has advantages over other research topics. The high-speed 
development period of the research topic of media literacy education is from 2010 to 2013, and it has been developing steadily since then; Other research topics such as Internet media literacy, new media, self-media, etc. also got some attention, and although their emergence time is later than the former, the state of their high attention has continued to 2019. This shows that these emerging research topics have a certain vitality (Hobbs, 2006), and they have strong practical significance and research value at present. It is predicted that in the next period of time, research topics such as Internet media literacy, new media and self-media will continue to maintain a high degree of research heat (Hu \& Wang, 2007), and the heat of research related to media literacy education will be roughly the same as that of media literacy research, showing a stable and slightly declining research trend.

As an important part of media literacy research and social studies (Stein \& Prewett, 2009), school media literacy education is the focus of many researchers in the past. At present, although the government is providing supports for media literacy education, the imperfection of the policy, the lack of teachers and teacher training programs have seriously hindered the implementation and development of media literacy education (Cheung, 2009; Ivanović, 2014). Therefore, the improvement of the policies and the cultivation of media literacy talents are still problems that cannot be ignored in China.

In many figures of analysis results, Internet, public opinion, political education and other terms are mentioned. The trend it presents is that media literacy will continue to expand its research scope (Hu \& Wang, 2007). Combined with the current development of media literacy research, media literacy research in the future will be more closely related to society and life, more in line with the development of the times, and with a stronger practical significance and research value (Hu \& Wang, 2007), rather than just a kind of theoretical research. At the same time, due to the strong inclusiveness of media literacy (Leurs, Omerovié, Bruinenberg, \& Sprenger, 2018), the future research of media literacy will be more interdisciplinary and integrate with more fields (Schwarz, 2003; Geng \& $\mathrm{Xu}, 2014)$.

\subsection{Deficiencies and Limitations of the Conclusions}

Although several conclusions and research results have been obtained, it has to say that there are still some shortcomings and limitations in the conclusions. First of all, there are many ways of visual analysis with CiteSpace tools. The results may also produce some differences by using different analysis methods. There are only several analysis methods used here, mainly including keywords co-occurrence analysis, keywords clustering analysis, keywords timeline analysis, keywords burst detection analysis. Secondly, the description of the current situation and the prediction of the trend are both based on the analysis of the existing research visualization data. Due to the limitations of researchers' vision and ability, it is inevitable that there may be some deviations in the research conclusions, 
especially in the prediction of trends. Hope that the follow-up research can continue to improve these deficiencies.

\section{Funding}

This research was supported by the Priority Academic Program Development of Jiangsu Higher Education Institutions in China.

\section{Author Contributions}

Ying Chen designed the research at the beginning. Qi Su analyzed the data, and prepared the first draft of the paper. Ying Chen as the corresponding author contributed to the revision. All authors approved the final draft.

\section{Conflicts of Interest}

The authors declare no conflicts of interest regarding the publication of this paper.

\section{References}

Anderson, J. A. (1981). Receivership Skills: An Educational Response. In M. E. Ploghoft, \& J. A. Anderson (Eds.), Education in a Television Age (pp. 19-27). Springville, $\mathrm{OH}$ : Charles Thomas. https://files.eric.ed.gov/fulltext/ED203395.pdf\#page=17

Cheung, C. K. (2009). Media Education in Asia. Berlin: Springer Science \& Business Media. https://doi.org/10.1007/978-1-4020-9529-0

Cheung, C. K. (2016). Media Literacy Education in China. Singapore: Springer. https://doi.org/10.1007/978-981-10-0045-4

Cubbage, J. (2018). Handbook of Research on Media Literacy in Higher Education Environments. Hershey, PA: IGI Global. https://doi.org/10.4018/978-1-5225-4059-5

Franco, M., \& Pinho, C. (2019). A Case Study about Cooperation between University Research Centres: Knowledge Transfer Perspective. Journal of Innovation \& Knowledge, 4, 62-69. https://doi.org/10.1016/j.jik.2018.03.003

Frau-Meigs, D., \& Torrent, J. (2009). Media Education Policy: Towards a Global Rationale. Comunicar, 16, S15. https://doi.org/10.3916/c32-2009-01-001

Fu, H., Hu, T., Wang, J., Feng, D., Fang, H., Wang, M., Tang, S., Yuan, F., \& Feng, Z. (2015). A Bibliometric Analysis of Malaria Research in China during 2004-2014. Malaria Journal, 14, 195. https://doi.org/10.1186/s12936-015-0715-2

Geng, Y. Q., \& Wang, P. F. (2016). The Evolution Trend of EU Media Literacy Policy in the Digital Environment. Modern Communication (Journal of Communication University of China), 38, 147-151.

http://dx.chinadoi.cn/10.3969/j.issn.1007-8770.2016.01.025

Geng, Y., \& Xu, Y. (2014). The Development of Media Literacy Curriculum in Foreign Countries and Its Future Development during the Years of 2003 and 2013. China Educational Technology, No. 12, 31-37. http://dx.chinadoi.cn/10.3969/j.issn.1006-9860.2014.12.006

Hobbs, R. (2006). Multiple Visions of Multimedia Literacy: Emerging Areas of Synthesis. In M. McKenna, L. Labbo, R. Kiefer, \& D. Reinking (Eds.), International Handbook of Literacy and Technology (Vol. 2, pp. 15-28). Mahwah, NJ: Lawrence Erlbaum. https://doi.org/10.4324/9780203929131 
Hu, L. L., \& Wang, J. Q. (2007). Advancement and Imperfection of Media Literacy Research in Mainland China. Journal of Hebei University (Philosophy and Social Science), 32, 26-32.

Ivanović, M. (2014). Development of Media Literacy: An Important Aspect of Modern Education. Procedia-Social and Behavioral Sciences, 149, 438-442. https://doi.org/10.1016/j.sbspro.2014.08.284

Koltay, T. (2011). The Media and the Literacies: Media Literacy, Information Literacy, Digital Literacy. Media, Culture \& Society, 33, 211-221. https://doi.org/10.1177/0163443710393382

Leurs, K., Omerović, E., Bruinenberg, H., \& Sprenger, S. (2018). Critical Media Literacy through Making Media: A Key to Participation for Young Migrants? Communications, 43, 427-450. https://doi.org/10.1515/commun-2018-0017

Livingstone, S., Papaioannou, T., Pérez, M. D. M. G., \& Wijnen, C. W. (2012). Critical Insights in European Media Literacy Research and Policy. Media Studies, 3, 1-176. https://hrcak.srce.hr/ojs/index.php/medijske-studije/article/view/6063/3155

Manville, C., Hinrichs, S., Parks, S., Kamenetzky, A., Gunashekar, S., Wilkinson, B., \& Grant, J. (2015). Characteristics of High-Performing Research Units: A Preliminary Analysis. https://dera.ioe.ac.uk/24744/1/2015_highperform.pdf

Potter, W. J. (2010). The State of Media Literacy. Journal of Broadcasting \& Electronic Media, 54, 675-696. https://doi.org/10.1080/08838151.2011.521462

Schwarz, G. (2003). Renewing the Humanities through Media Literacy. Journal of Curriculum \& Supervision, 19, 44-53.

http://web.a.ebscohost.com/ehost/viewarticle/render?data=dGJyMPPp44rp2\%2fdV0\% 2bnjisfk5Ie46bJPr6i0SrKk63nn5Kx95uXxjL6qrUqypbBIsKaeSrios1KwqJ5Zy5zyit\%2fk8 Xnh6ueH7N\%2fiVaunsk63q7FNsae0PurX7H\%2b78OZF4eSkfOCz34vsnPJ55bO\%2fZq TX7FWvp65NtKawSaTc7Yrr1\%2fJV7trkXvPi6mzj7vIA\&vid=1\&sid=6a0c6620-d42f-4e 7c-9194-a1f1724d690b@sessionmgr4008

Siverblatt, A., Eliceiri, E. M. E., \& Eliceiri, E. M. (1997). Dictionary of Media Literacy. Santa Barbara, CA: Greenwood Publishing Group.

https://books.google.com/books?hl=zh-CN\&lr=\&id=SxuLleZCuVUC\&oi=fnd\&pg=PR $\underline{7 \& d q=\text { Dictionary }+ \text { of }+ \text { media }+ \text { literacy }+ \text { Silverblatt\&ots=MUdv1Mv7ri\&sig=qupgNii5-B }}$ S43tp_6Ed_jOEDiiA\#v=onepage\&q\&f=false

Stein, L., \& Prewett, A. (2009). Media Literacy Education in the Social Studies: Teacher Perceptions and Curricular Challenges. Teacher Education Quarterly, 36, 131-148. https://files.eric.ed.gov/fulltext/EJ851033.pdf

Thoman, E. (1999). Skills and Strategies for Media Education. Educational Leadership, $56,50-54$.

http://www.medialit.org/reading-room/skills-strategies-media-education\#bio

Tian, Q., Zhang, J., Tang, C., Wang, L., Fang, J., \& Zhang, Z. (2020). Research Topics and Future Trends on Maker Education in China Based on Bibliometric Analysis. International Journal of Information and Education Technology, 10, 135-139.

https://doi.org/10.18178/ijiet.2020.10.2.1352

Wu, P. Z., \& Du, S. Y. (2011). A Study on the Media Literacy of Chinese College Students. China Educational Technology, 2, 29-32.

http://dx.chinadoi.cn/10.3969/j.issn.1006-9860.2011.02.006

Zhao, L., \& Zhang, S. Y. (2015). Media Literacy Research Hotspot and Trend Analysis-Based on CSSCI (2012-2013) Source Journal Data of Pedagogy, Journalism and Communication. E-Education Research, 36, 17-25. 
Zhao, M. C., \& Liu, W. Q. (2015). On the Media Literacy Education in America: History, Problems and Developing Trends. Primary \& Secondary Schooling Abroad, 4, 16-20. http://dx.chinadoi.cn/10.3969/j.issn.1007-8495.2015.04.004 